\section{Case Reports in Ophthalmology}

\begin{tabular}{|c|c|}
\hline \multicolumn{2}{|c|}{ Case Rep Ophthalmol 2013;4:155-159 } \\
\hline $\begin{array}{l}\text { DOI: 10.1159/000355389 } \\
\text { Published online: September 28, } 2013\end{array}$ & $\begin{array}{l}\text { (c) } 2013 \text { S. Karger AG, Basel } \\
1663-2699 / 13 / 0043-0155 \$ 38.00 / 0 \\
\text { www.karger.com/cop }\end{array}$ \\
\hline
\end{tabular}

This is an Open Access article licensed under the terms of the Creative Commons Attribution-NonCommercial 3.0 Unported license (CC BY-NC) (www.karger.com/OAlicense), applicable to the online version of the article only. Distribution permitted for noncommercial purposes only.

\title{
Punctate Inner Choroidopathy: A Clinical Case Report
}

\author{
Joana Campos António Campos Diana Beselga Sílvia Mendes \\ Arminda Neves J.P. Castro Sousa \\ Ophthalmology Department, Leiria-Pombal Hospital Center, Leiria, Portugal
}

\section{Key Words}

Punctate inner choroidopathy · Choroidal neovascularization · Intravitreal bevacizumab

\begin{abstract}
Purpose: To report an uncommon case of a 29-year-old Caucasian male diagnosed with unilateral choroidal neovascularization (CNV) secondary to punctate inner choroidopathy leading to visual impairment. Methods: This is a retrospective and descriptive case report based on data from clinical records, patient observation and analysis of ancillary diagnostic tests. Results: A 29-year-old Caucasian male presented to our emergency department with complaints of decreased central vision in his left eye (LE), detected a few hours before. Bestcorrected visual acuity (BCVA) in the LE was counting fingers at $50 \mathrm{~cm}$ and BCVA in the right eye was 20/20. Fundoscopy of the LE evidenced multiple round and yellowish lesions in the macula and nasal to the optic nerve, without intraocular inflammation signs. Optical coherence tomography showed increased retinal thickness with detachment of the neuroepithelium and a slight retinal pigment epithelium detachment. Fluorescein angiography revealed hyperfluorescent lesions with blurred borders in the macula. An intravitreal injection of bevacizumab $(1.25 \mathrm{mg} / 0.05 \mathrm{ml})$ was administered in the $L E$, which resulted in anatomic and visual improvement. Conclusion: We present a rare case of unilateral CNV secondary to punctate inner choroidopathy in a young, myopic male.
\end{abstract}

(C) 2013 S. Karger AG, Basel

\section{Introduction}

The term punctate inner choroidopathy (PIC) was first used by Watzke et al. [1] in 1984 to describe findings in a group of patients with multifocal, well-circumscribed, small choroidal lesions. 
Campos et al.: Punctate Inner Choroidopathy: A Clinical Case Report

PIC is an infrequent ocular inflammatory disease, mostly affecting young myopic women. Typically, patients present with symptoms of loss of central visual acuity, as well as photopsia and scotomata. Diagnosis was based on the visualization of multiple, small (between 100 and $300 \mu \mathrm{m}$ ), round, yellowish-white punctate lesions on fundoscopy, in the absence of ocular inflammation elsewhere in the eye (vitritis, pars planitis, anterior chamber cells or anterior synechiae) [1,2]. These lesions appear to be located at the level of the choroid and the retinal pigment epithelium (RPE) and may coalesce and form a serous retinal detachment $[1,3]$.

Spectral-domain optical coherence tomography (SD-OCT) may be able to provide detailed structural characteristics of PIC lesions and may be a useful, noninvasive way of identifying disease activity in patients with PIC. Furthermore, Channa et al. [3] suggested that SD-OCT may provide information of disease activity that is not detected clinically or on fluorescein angiography (FA).

The lesions fill and stain during the late phase of FA. Autofluorescence images show hypofluorescence in cicatricial lesions and autofluorescence in active lesions [2].

PIC is usually a benign disease, with visual prognosis ordinarily favorable [4], but severe visual loss can occur if complicated by choroidal neovascularization (CNV) and subretinal fibrosis: rates of up to 69 and 56\%, respectively, were reported [3]. These complications usually occur within 1 year of presentation [5]. Later, these lesions progress to hypopigmented, pigmented or hyperplastic fibrotic scars [2].

The management of CNV due to PIC has not been conclusively determined, so a variety of treatment options have been described: submacular surgery [6], laser photocoagulation, photodynamic therapy [4], immunosuppressants [7], intravitreal and systemic corticoids [8, 9] and intravitreal anti-VEGF agents [10-12].

\section{Case Report}

A 29-year-old Caucasian male presented to our emergency department with complaints of decreased central vision in his left eye (LE), detected a few hours before. Ten years before, he had undergone ophthalmic surgery with phakic lens implantation due to high myopia in both eyes. The patient was taking benzodiazepines and beta-blockers due to panic disorder. He denied systemic disease known to be associated with choroiditis, systemic symptoms or recent illness. There was no relevant family history.

Best-corrected visual acuity (BCVA) in the LE was counting fingers at $50 \mathrm{~cm}$. He described having blurred central vision in the LE tested on the Amsler grid. Fundoscopy of the LE evidenced multiple, round and yellowish lesions in the macula and nasal to the optic nerve, without signs of intraocular inflammation (fig. 1, left). BCVA in the right eye was $20 / 20$, and ophthalmological examination showed slight changes of the RPE.

OCT showed increased retinal thickness with detachment of the neuroepithelium and a slight RPE detachment in the LE (fig. 1, middle). FA revealed hyperfluorescent lesions with blurred borders in the macula (fig. 1, right).

We performed a chest X-ray and an analytic study to exclude autoimmune and infectious diseases. Afterwards an intravitreal injection of bevacizumab $(1.25 \mathrm{mg} / 0.05 \mathrm{ml})$ was administered in the LE, showing a significant reduction of the neuroepithelial detachment (fig. 2). Four months later, BCVA in the LE was 20/200 and no increased retinal thickness was seen on OCT. 
Campos et al.: Punctate Inner Choroidopathy: A Clinical Case Report

One year later, the patient was reexamined and showed a BCVA of 20/40 in the LE. FA and OCT appearances confirmed no active lesions, and fundoscopy revealed a chorioretinal scar on papillomacular beam (fig. 3 ). The same findings were also observed 2 years later.

\section{Discussion}

PIC is more common in young, Caucasian females; nevertheless, it can occur among men, non-Caucasians and hyperopes [5]. We presented a case of a young, Caucasian and myopic male.

Essex et al. [13] found that, at the initial visit, $47 \%$ of patients had unilateral disease at baseline, with $77 \%$ of them having PIC lesions and CNV and 23\% having PIC lesions only. On the other hand, Brown et al. [14] reported that $88 \%$ of patients with PIC had bilateral disease. Channa et al. [3] found that the majority of lesions (89\%) in their study, irrespective of clinical activity, showed involvement of the RPE, including RPE elevation with sub-RPE signals and RPE discontinuity. Our patient presented with PIC lesions and CNV in the LE and also subtle RPE changes in the right eye.

It is known that PIC may lead to the development and growth of CNV. In recent years, studies analyzing the use of intravitreal anti-VEGF for treating CNV in PIC have been published and have shown good results $[10,12]$.

In our case report, one single injection of intravitreous bevacizumab produced anatomic and visual improvement. There was resolution of the serous retinal detachment after treatment, but there was no prompt restoration of BCVA. Interestingly, there was a considerable improvement of visual acuity 1 year after treatment.

Chan et al. [12] reported 4 patients with PIC treated with 3 injections of intravitreal bevacizumab. All improved and none had a BCVA of worse than 20/40 at final examination. Moreover, Leung et al. [15] reported a case of PIC complicated by CNV treated successfully with a single injection of intravitreal ranibizumab with no recurrence at 8 months.

Our patient showed no recurrence after 2 years of follow-up. Even though some authors used 3 monthly injections of anti-VEGF, we used only 1 injection with the purpose of administering additional injections as needed based on clinical examination and OCT.

Mangat et al. [11] proposed that due to the good visual outcomes and lack of complications, anti-VEGF treatment should be the first-line treatment in these cases. Furthermore, frequent follow-up for a long period to identify and treat any recurrence is recommended.

Frequently, patients who suffer from PIC have a delayed diagnosis [5]. Given that PIC could be associated with serious complications, such as CNV and subretinal fibrosis, mainly within the first year of disease, early diagnosis and close monitoring is beneficial in order to manage these complications promptly.

\section{Disclosure Statement}

Neither author has a financial or proprietary interest in any material or method mentioned. 


\begin{tabular}{l|l}
\hline Case Rep Ophthalmol 2013;4:155-159 \\
\hline DOI: 10.1159/000355389 & $\begin{array}{l}\text { C 2013 S. Karger AG, Basel } \\
\text { www.karger.com/cop }\end{array}$ \\
\hline
\end{tabular}

Campos et al.: Punctate Inner Choroidopathy: A Clinical Case Report

\section{References}

1 Watzke RC, Packer AJ, Folk JC, Benson WE, Burgess D, Ober RR: Punctate inner choroidopathy. Am J Ophthalmol 1984;98:572-584.

2 American Academy of Ophthalmology, The Eye M.D. Association: Focal and diffuse choroidal and retinal inflammation; in Basic and Clinical Science Course, section 12: Retina and Vitreous. Leo, 2011-2012.

-3 Channa R, Ibrahim M, Sepah Y, Turkcuoglu P, Lee JH, Khwaja A, Hatef E, Bittencourt M, Heo J, Do DV, Nguyen QD: Characterization of macular lesions in punctate inner choroidopathy with spectral domain optical coherence tomography. J Ophthalmic Inflamm Infect 2012;2:113-120.

-4 Brouzas D, Charakidas A, Rotsos T, Moschos MM, Loukianou H, Koutsandrea C, Ladas I, Baltatzis S: Choroidal neovascularization due to punctuate inner choroidopathy: long-term follow-up and review of literature. Clin Ophthalmol 2010;4:871-876.

-5 Gerstenblith AT, Thorne JE, Sobrin L, Do DV, Shah SM, Foster CS, Jabs DA, Nguyen QD: Punctate inner choroidopathy: a survey analysis of 77 persons. Ophthalmology 2007;114:1201-1204.

6 Olsen TW, Capone A, Sternberg P, Grossniklaus HE, Martin DF, Aaberg TM: Subfoveal choroidal neovascularization in punctate inner choroidopathy. Surgical management and pathologic findings. Ophthalmology 1996;103:2061-2069.

-7 Turkcuoglu P, Chang PY, Rentiya ZS, Channa R, Ibrahim M, Hatef E, Sophie R, Sadaka A, Wang J, Sepah YJ, Do DV, Foster CS, Nguyen QD: Mycophenolate mofetil and fundus autofluorescence in the management of recurrent punctate inner choroidopathy. Ocul Immunol Inflamm 2011;19:286-292.

$>8$ Levy J, Shneck M, Klemperer I, Lifshitz T: Punctate inner choroidopathy: resolution after oral steroid treatment and review of the literature. Can J Ophthalmol Oct 2005;40:605-608.

-9 Chan WM, Lai TY, Lau TT, Lee VY, Liu DT, Lam DS: Combined photodynamic therapy and intravitreal triamcinolone for choroidal neovascularization secondary to punctate inner choroidopathy or of idiopathic origin: one-year results of a prospective series. Retina 2008;28:71-80.

-10 Valverde Megías A, Arriola Villalobos P, Reche Frutos J, Donate López J, Calvo González C, García Feijoo J: Intravitreal ranibizumab (Lucentis ${ }^{\circledR}$ ) in the treatment of choroidal neovascular membrane secondary to punctate inner choroidopathy. Arch Soc Esp Oftalmol 2010;85:149-152.

11 Mangat SS, Ramasamy B, Prasad S, Walters G, Mohammed M, Mckibbin M: Resolution of choroidal neovascularization secondary to punctate inner choroidopathy (PIC) with intravitreal anti-VEGF agents: a case series. Semin Ophthalmol 2011;26:1-3.

12 Chan WM, Lai TY, Liu DT, Lam DS: Intravitreal bevacizumab (avastin) for choroidal neovascularization secondary to central serous chorioretinopathy, secondary to punctate inner choroidopathy, or of idiopathic origin. Am J Ophthalmol 2007;143:977-983.

-13 Essex RW, Wong J, Fraser-Bell S, Sandbach J, Tufail A, Bird AC, Dowler J: Punctate inner choroidopathy: clinical features and outcomes. Arch Ophthalmol 2010;128:982-987.

-14 Brown J, Folk JC, Reddy CV, Kimura AE: Visual prognosis of multifocal choroiditis, punctate inner choroidopathy, and the diffuse subretinal fibrosis syndrome. Ophthalmology 1996;103:1100-1105.

15 Leung A, Weisbrod D, Schwartz C: Intravitreal ranibizumab in the treatment of choroidal neovascular membrane secondary to punctate inner choroidopathy. Can J Ophthalmol 2010;45:3:300-301.
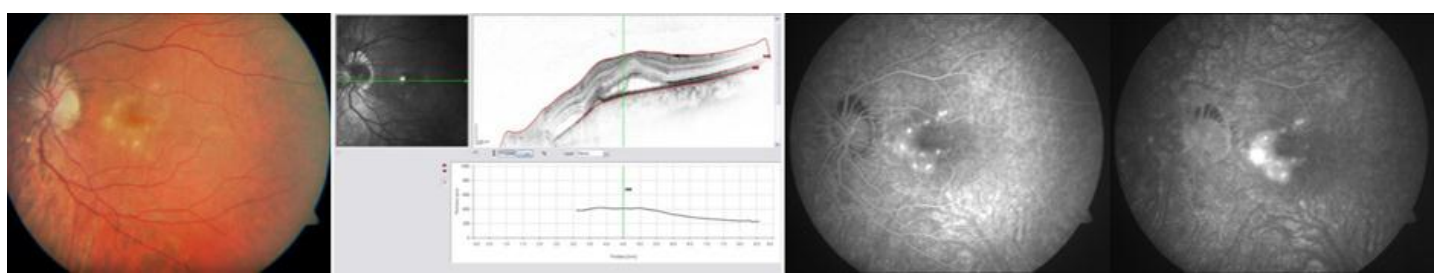

Fig. 1. Retinography of the LE showing multiple, round and yellowish lesions in the macula and nasal to the optic nerve (left). OCT with detachment of the neuroepithelium and a slight RPE detachment (middle) and FA revealing hyperfluorescent lesions (right) at presentation. 

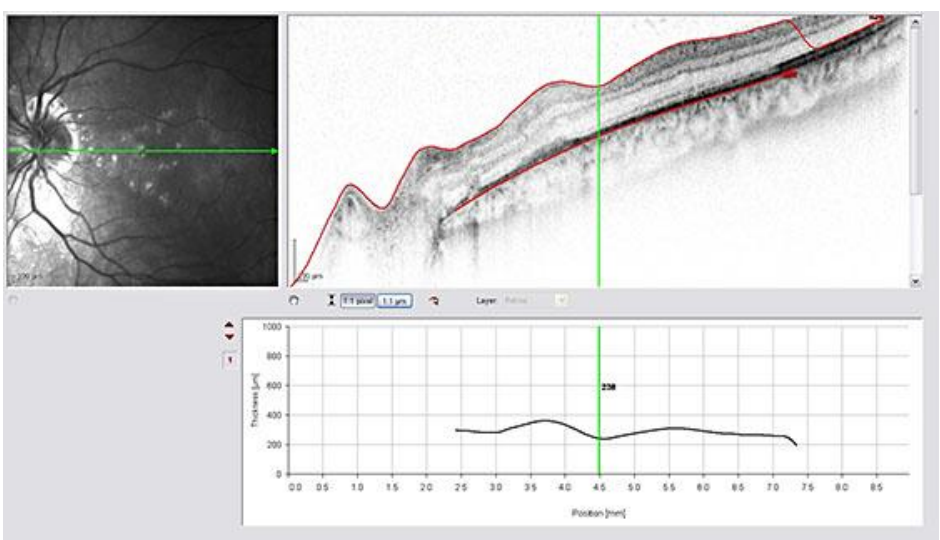

Fig. 2. OCT of the LE showing significant reduction of the neuroepithelial detachment after intravitreal injection of bevacizumab $(1.25 \mathrm{mg} / 0.05 \mathrm{ml})$.

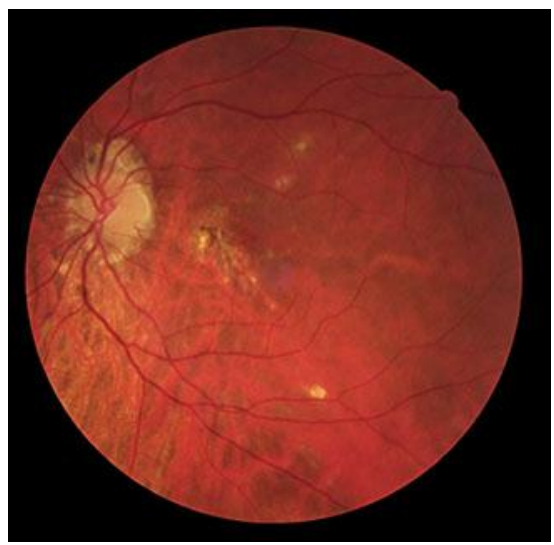

Fig. 3. Retinography of the LE performed 1 year later, revealing a chorioretinal scar. 